\title{
Physics of Mass
}




\section{Physics of Mass}

Edited by

\section{Behram N. Kursunoglu}

Global Foundation, Inc.

Coral Gables, Florida

\section{Stephan L. Mintz}

Florida International University

Miami, Florida

and

\section{Arnold Perlmutter}

University of Miami

Coral Gables, Florida

Kluwer Academic Publishers

New York, Boston, Dordrecht, London, Moscow 
eBook ISBN: $\quad 0-306-47085-3$

Print ISBN: $\quad 0-306-46029-7$

(C2002 Kluwer Academic Publishers

New York, Boston, Dordrecht, London, Moscow

Print @1998 Kluwer Academic Publishers

New York

All rights reserved

No part of this eBook may be reproduced or transmitted in any form or by any means, electronic, mechanical, recording, or otherwise, without written consent from the Publisher

Created in the United States of America

Visit Kluwer Online at: http://kluweronline.com and Kluwer's eBookstore at:

http://ebooks.kluweronline.com 


\section{PREFACE}

The $26^{\text {th }}$ Conference on Orbis Scientiae 1997 is the second in this series of high energy physics and cosmology that took place in the month of December instead of the well established tradition where the month of January was the conference date. This change was due to the increased hotel rates in South Florida. Another change in the organization of these conferences is the choice of a core topic to take half of the conference time. The remaining time will be devoted to subjects of direct interest to participants. In the 1997 Orbis Scientiae we chose "Physics of Mass" as the core topic of the conference, which took over five sessions. The remaining five sessions were devoted to those presentations of direct interest to some of the participants.

The Orbis Scientiae 1998 will cover "The Physics of Spin" as a core topic. In anticipation of the ascending importance of gravity research in the $21^{\text {st }}$ century, for the core topics for the Orbis Scientiae 1999 and 2000 we suggest "The Status of An Evolving Cosmological Parameter" and "The Nature of Gravity from Big Bang to Flat Universe", respectively. These two topics may be expected to lead on to the first conference in the $21^{\text {st }}$ century in which the core topic should be chosen for the Orbis Scientiae 2001 by the participants. We are pleased to invite the conference participants to send us their choices of core topics.

The Trustees and the Chairman of the Global Foundation, Inc., wish to extend special thanks to Edward Bacinich of Alpha Omega Research Foundation for his continuing generous support including the 1997 Orbis Scientiae.

Behram N. Kursunoglu

Stephan L. Mintz Arnold Perlmutter

Coral Gables, Florida

April 1998 


\section{ABOUT THE GLOBAL FOUNDATION, INC.}

The Global Foundation, Inc., which was established in 1977, utilizes the world's most important resource... people. The Foundation consists of great senior men and women of science and learning, and of outstanding achievers and entrepreneurs from industry, governments, and international organizations, along with promising and enthusiastic young people. These people form a unique and distinguished interdisciplinary entity, and the Foundation is dedicated to assembling all the resources necessary for them to work together. The distinguished senior component of the Foundation transmits its expertise and accumulated experience, knowledge, and wisdom to the younger membership on important global issues and frontier problems in science.

Our work, therefore, is a common effort, employing the ideas of creative thinkers with a wide range of experience and viewpoints.

\section{GLOBAL FOUNDATION BOARD OF TRUSTEES}

Behram N. Kursunoglu, Global Foundation, Inc., Chairman of the Board, Coral Gables.

M. Jean Couture, Former Secretary of Energy of France, Paris

Manfred Eigen *, Max-Planck-Institut, Göttingen

Willis E. Lamb*, Jr., University of Arizona

Louis Néel*, Université de Gronoble, France

Frederick Reines*, University of California at Irvine

Glenn T. Seaborg*, Lawrence Berkeley Laboratory

Henry King Stanford, President Emeritus, Universities of Miami and Georgia

*Nobel Laureate 


\section{GLOBAL FOUNDATION'S RECENT CONFERENCE PROCEEDINGS}

Making the Market Right for the Efficient Use of Energy

Edited by: Behram N. Kursunoglu

Nova Science Publishers, Inc., New York, 1992

Unified Symmetry in the Small and in the Large

Edited by; Behram N. Kursunoglu, and Arnold Perlmutter

Nova Science Publishers, Inc., New York, 1993

Unified Symmetry in the Small and in the Large - 1

Edited by: Behram N. Kursunoglu, Stephan Mintz, and Arnold Perlmutter Plenum Press, 1994

Unified Symmetry in the Small and in the Large - 2

Edited by; Behram N. Kursunoglu, Stephan Mintz, and Arnold Perlmutter Plenum Press, 1995

Global Energy Demand in Transition: The New Role of Electricity

Edited by: Behram N. Kursunoglu, Stephan Mintz, and Arnold Perlmutter Plenum Press, 1996

\section{Economics and Politics of Energy}

Edited by; Behram N. Kursunoglu, Stephan Mintz, and Arnold Perlmutter Plenum Press, 1996

Neutrino Mass, Dark Matter, Gravitational Waves, Condensation of Atoms and Monopoles, Light Cone Quantization

Edited by; Behram N. Kursunoglu, Stephan Mintz, and Arnold Perlmutter Plenum Press, 1996

Technology for the Global Economic, Environmental Survival and Prosperity

Edited by: Behram N. Kursunoglu, Stephan Mintz, and Arnold Perlmutter Plenum Press, 1997

25th Coral Gables Conference on High Energy Physics and Cosmology Edited by: Behram N. Kursunoglu, Stephan Mintz, and Amold Perlmutter Plenum Press, 1997

\section{Environment and Nuclear Energy}

Edited by: Behram N. Kursunoglu, Stephan Mintz, and Arnold Perlmutter Plenum Press, 1998

\section{6th Coral Gables Conference on Physics of Mass}

Edited by: Behram N. Kursunoglu, Stephan Mintz. and Arnold Perlmutter

Plenum Press, 1998 


\section{CONTRIBUTING CO-SPONSORS OF THE GLOBAL FOUNDATION CONFERENCES}

Electric Power Research Institute, Palo Alto, California

Gas Research Institute, Washington, DC

General Electric Company, San Jose, California

Northrop Grumman Aerospace Company, Bethpage, New York

Martin Marietta Astronautics Group, Denver, Colorado

Black and Veatch Company, Kansas City, Missouri

Bechtel Power Corporation, Gaithersburg, Maryland

ABB Combustion Engineering, Windsor, Connecticut

BellSouth Corporation, Atlanta, Georgia

National Science Foundation

United States Department of Energy 


\section{ORBIS SCIENTIAE 1997 - II PROGRAM}

FRIDAY, December 12, 1997

$\begin{array}{lr}\text { 8:00 AM - Noon } & \text { REGISTRATION } \\ \text { 1:30 PM } & \text { SESSION I: } \\ & \text { Moderators: }\end{array}$

Dissertators:

Annotators:

Session Organizer:

3:15 PM

3:30 PM

\section{COFFEE BREAK}

SESSION II:

Moderator:

Dissertators:

Annotators:

Session Organizer:

\section{GRAVITATIONAL MASS}

BEHRAM N. KURSUNOGLU, Global Foundation, Inc., Coral Gables, Florida

\section{BEHRAM N. KURSUNOGLU}

"Origin of Mass"

SYDNEY MESHKOV, CALTECH

"Current Status of LIGO'

CHRIS POPE, Texas A \& M, College Station, Texas

"Gauge Dyonic Strings in Six Dimensions"

JANNA LEVIN, University of California, Berkeley

BEHRAM N. KURSUNOGLU

\section{NEUTRINO MASSES}

PETER ROSEN, Department of Energy, Washington DC GEOFFREY MILLS, Los Alamos National Laboratory

JONNY KLEINFELLER, Forschungszentrum Karlsruhe "KARMEN-Upgrade: Improvement In The Search For Neutrino Oscillations And First Results"

GEOFFREY MILLS

"Results from the LSND Experiment"

SANJIB MISHRA, Harvard University

"Results from the NOMAD Experiment"

CHARLES LANE, Drexel University, Philadelphia,

Pennsylvania

"First Results from the CHOOZ Experiment"

LAWRENCE WAI, University of Washington, Seattle

"Atmospheric Neutrino Flux Mesurements with the Super-

Kamiokande Neutrino Obervatory"

STEPHAN MINTZ, Florida International University

6:00 PM - Welcoming Cocktails, Fontainebleau Cabana Area

7:00 PM Courtesy of Maria and Edward Bacinich

7:00 PM Orbis Scientiae Adjourns For The Day 
8:30 AM

10:30 AM

10:45 AM

\section{SESSION III:}

Moderators:

Dissertators:

Annotators:

Session Organizer:

\section{COFFEE BREAK}

SESSION IV:

Moderators:

Dissertators:

Annotators:

Session Organizer:

\section{PROGRESS ON NEW AND OLD IDEAS - I}

PAUL FRAMPTON, University of North Carolina at Chapel Hill

\section{PAUL FRAMPTON}

"Leptoquarks" SHELDON GLASHOW, Harvard University

"Tests of Lorentz Invariance"

O.W. GREENBERG, University of Maryland

"Spin-Statistics, Spin-Locality and TCP: Three Distinct Theorems"

GERALD GURALNIK, Brown University

"Numerical Field Theory on the Continuum"

ALAN KOSTELECKY, Indiana University

"Testing CPT Symmetry"

\section{SYDNEY MESHKOV, CALTECH}

PAUL FRAMPTON 
SESSION V:

Moderators:

Dissertators:

Annotators:

Session Organizer:

10:30 AM

10:45 AM

12:45 PM

1:30 PM
COFFEE BREAK

SESSION VI:

Moderator:

Dissertators:

Annotators:

Session Organizer:

\section{LUNCH BREAK}

SESSION VII:

Moderators:

Dissertators:
COSMOLOGICAL MASSES (BLACK HOLES, NEUTRON STARS, ETC.)

EDWARD KOLB, FERMI Laboratory, Chicago KATHERINE FREESE, University of Michigan

SCOTT DODELSON, FERMI Laboratory

"The CMB and Cosmological Parameters"

KATHERINE FREESE

"Massive Astrophysical Compact Halo Objects"

EDWARD KOLB

"Who is the Inflation?"

VIGDOR L. TEPLITZ, Southern Methodist University

"Mass of the Kuiper Belt"

EDWIN TURNER, Princeton University

"Gravitational Lens Determinations of the Mass and Age of the Universe"

FRANCESCO ANTONUCCIO, The Ohio State University EDWARD KOLB, FERMI Laboratory, Chicago

\section{PROGRESS ON NEW AND OLD IDEAS - II}

GEOFFREY WEST, LANL

ROBERT BLUHM, Colby College

"Testing CPT in Atomic Physics"

GERALD B. CLEAVER, University of Pennsylvania "Mass Heirarchy and Flat Directions in String Models" ZACHARY G URALNIK, Princeton University

"Branes, Torons, and Yang-Mills Dualities"

PAOLO PRIVITERA, University of Rome, Italy

"Measurement of the Mass of the Intermediate Vector Bosons"

RICHARD P. WOODARD

"Particles As Bound States In Their Own Potential"

KATSUMI TANAKA, Ohio State University

STEPHAN MINTZ

\section{SUSY MASSES}

RICHARD ARNOWITT, Texas A\&M University

\section{RICHARD ARNOWITT}

"Non-Universal Soft SUSY Breaking"

STEPHANE FICHET, LPNHE, Paris France

"Status of Higgses and SUSY Mass Limits at LEP"

CHUNG KAO, University of Wisconsin

"Infrared Fixed Point Results in mSUGRA Models"

STEPHAN MINTZ

"Observing the Weak Interaction in Polarized Parity Violating Electron Scattering" 


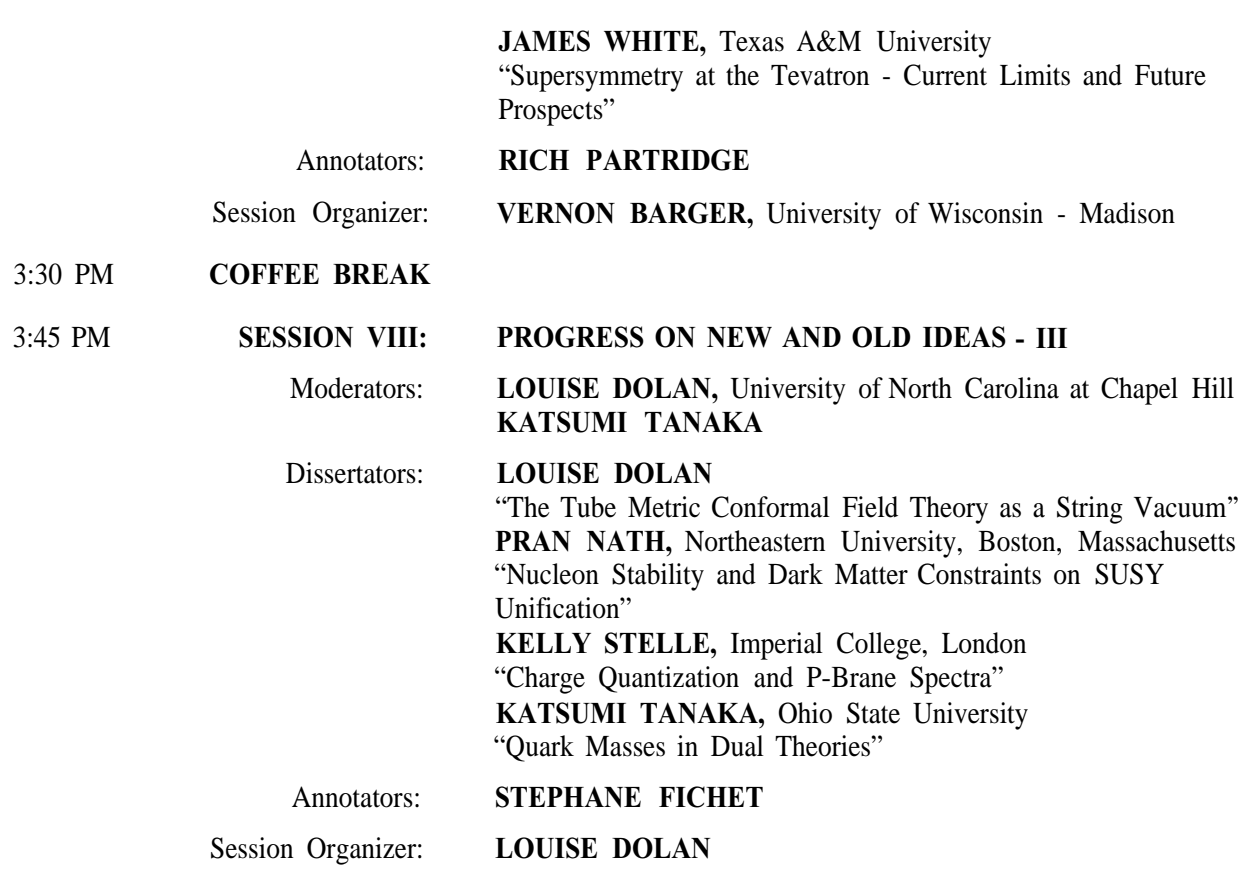

5:30 PM Conference Adjourns for the Day

MONDAY, December 15, 1997

\begin{tabular}{|c|c|c|}
\hline \multirow[t]{5}{*}{ 8:30 AM } & SESSION IX: & PROGRESS ON NEW AND OLD IDEAS \\
\hline & Moderators: & $\begin{array}{l}\text { STEPHEN PINSKY, Ohio State University } \\
\text { FRED ZACHARIASEN, CALTECH }\end{array}$ \\
\hline & Dissertators: & $\begin{array}{l}\text { FRANCESCO ANTONUCCIO } \\
\text { "DLCQ of Supersymmetric Matrix Models" } \\
\text { BRIAN MEADOWS, University of Cincin } \\
\text { "BaBar Experiment at SLAC" } \\
\text { TERRY WALKER, Ohio State University } \\
\text { "Primordial Lithium and the Baryonic Mass }\end{array}$ \\
\hline & Annotators: & ARNOLD PERLMUTTER, University of \\
\hline & Session Organizer: & STEPHEN PINSKY, Ohio State University \\
\hline 10:15 AM & COFFEE BREAK & \\
\hline \multirow[t]{5}{*}{ 10:30 AM } & SESSION X: & BIG BANG CREATION OF MASS \\
\hline & Moderators: & EDWARD KOLB \\
\hline & Dissertators: & $\begin{array}{l}\text { JOSH FRIEMAN, FERMI Laboratory } \\
\text { "The Distribution of Mass in the Universe" } \\
\text { CHRIS HILL, FERMI Laboratory } \\
\text { "A Brief History of Mass" } \\
\text { PIERRE RAMOND } \\
\text { "The Issue of Mass" }\end{array}$ \\
\hline & Annotators: & BEHRAM KURSUNOGLU \\
\hline & Session Organizer: & EDWARD KOLB \\
\hline
\end{tabular}

12:30 PM ORBIS SCIENTIAE 1997 - II ADJOURNS

xii 


\section{CONTENTS}

\section{SECTION I \\ Gravitational Mass}

A New Cosmological Parameter Spanning the Microcosm and Macrocosm . . . . . . 3 Behram N. Kursunoglu

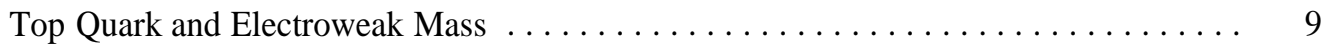

Christopher T. Hill

Anti-de Sitter Black Holes and Their Superpartners in $2+1$ Dimensions $\ldots \ldots \ldots .19$

Sharmanthie Fernando and Freydoon Mansouri

The Case for a Standard Model with Anomalous $U(1) \ldots \ldots \ldots \ldots \ldots \ldots \ldots \ldots$

Pierre Ramond

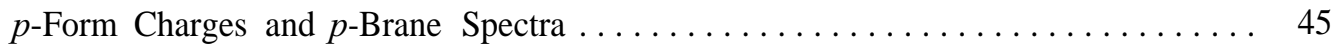

K. S. Stelle

\section{SECTION II \\ Neutrino Masses}

KARMEN-Upgrade: Improvement in the Search for Neutrino Oscillations and

First Results

J. Kleinfeller et al.

Atmosphere Neutrino Flux Studies with the Super-Kamiokande Detector

Lawrence Wai

Numerical Field Theory on the Continuum

Stephen Hahn and G. S. Guralnik

\section{SECTION III \\ Progress on New and Old Ideas}

Leptoquarks Revisited

Paul H. Frampton

The Relation of Spin, Statistics, Locality and TCP

O. W. Greenberg 
Tests of CPT and Lorentz Symmetry in Penning-Trap Experiments . . . . . . . . .

Robert Bluhm, V. Alan Kostelecký, and Neil Russell

Mass Hierarchy and Flat Directions in Sting Models

Gerald B. Cleaver

Measurement of the Mass of the Intermediate Vector Bosons at LEP

Paolo Privitera

Polarized Parity Violating Electron Scattering on ${ }^{3} \mathrm{He}$ from Low to High Energy .....

S. L. Mintz, G. M. Gerstner, and M. A. Barnett

Guage Dyonic Strings and Their Global Limit

M. J. Duff, James T. Liu, H. Lü, and C. N. Pope

\section{SECTION IV \\ Particle Masses}

Quark Mass Hierarchy and Flavor Mixing

Harold Fritzsch

Quark Masses, B-Parameters, and CP Violation Parameters $\varepsilon$ and $\varepsilon^{\prime} / \varepsilon$

Rajan Gupta

\section{SECTION V \\ Progress on New and Old Ideas II}

Particles as Bound States in Their Own Potentials

R. P. Woodard

Enhanced Symmetries and Tensor Theories in Six Dimensions

L. Dolan

Quark Masses in Dual Theories

K. Tanaka

The Ba-Bar Experiment at SLAC

B. T. Meadows

On the Mass of the Kwiper Belt

V. L. Teplitz, D. C. Rosenbaum, R. J. Scalise, S. A. Stern, and J. D. Anderson

Nucleon Stability and Dark Matter Constraints on SUSY Unification

Pran Nath and R. Arnowitt

Large N Duality of Yang-Mills Theory on a Torus Zachary Guralnik

SUSY Masses with Non-Universal Soft Breaking

R. Arnowitt and Pran Nath

Index 